\title{
Docosahexaenoic Acid Inhibits Expression of Fibrotic Mediators in Mice With Chronic Pancreatitis
}

\author{
Sle Lee***, Yoo Kyung Jeong*, Joo Weon Lim, Hyeyoung Kim \\ Department of Food and Nutrition, Brian Korea 21 PLUS Project, College of Human Ecology, Yonsei University, Seoul, Korea
}

\begin{abstract}
Background: Chronic pancreatitis (CP) is an irreversible progressive disease that destroys exocrine parenchyma, which are replaced by fibrous tissue. As pancreatic fibrosis is a key feature of $\mathrm{CP}$, reducing fibrotic protein content in the pancreas is crucial for preventing CP. Studies suggest that NF- $\mathrm{kB}$ facilitates the expression of fibrotic mediators in pancreas and protein kinase C- $\delta$ (PKC- $\delta$ ) regulates NF- $\kappa B$ activation in stimulated pancreatic acinar cells. Docosahexaenoic acid (DHA) is an omega-3 fatty acid having anti-inflammatory and anti-fibrotic effects. It has been shown to inhibit NF-KB activity in cerulein-stimulated pancreatic acinar cells which is a cellular model of CP. In the present study, we investigated if DHA inhibits expression of fibrotic mediators by reducing PKC- $\delta$ and NF- $\mathrm{KB}$ expression in mouse pancreatic tissues with CP.

Methods: For six weeks, mice were weekly induced for acute pancreatitis to develop CP. Furthermore, acute pancreatitis was induced by hourly intraperitoneal injections of cerulein $(50 \mu \mathrm{g} / \mathrm{kg} \times 7)$. Mice were administered DHA $(10 \mu \mathrm{M})$ via drinking water before and after CP induction.

Results: Cerulein-induced pancreatic damages like decreased pancreatic weight/total body weight, leukocyte infiltration, necrosis of acinar cells, and vacuolization were found to be inhibited by DHA. Additionally, DHA inhibited cerulein-induced fibrotic mediators like alpha-smooth muscle actin and fibronectin in pancreas. DHA reduced expression of PKC- $\delta$ and NF- $\mathrm{B} B$ p65 in pancreatic tissues of cerulein-treated mice.
\end{abstract}

Conclusions: DHA may be beneficial in preventing CP by suppressing pancreatic expression of fibrotic mediators.

(J Cancer Prev 2019;24:233-239)

Key Words: Cerulein, Chronic pancreatitis, Docosahexaenoic acid, Fibrosis, Pancreas

\section{INTRODUCTION}

Chronic pancreatitis (CP) is characterized by dysregulated production of digestive enzymes, cytoplasmic vacuolization, fibrosis, and infiltration of inflammatory cells into the pancreas. It causes upper abdominal pain, digestive disorder, malnutrition, diabetes, and reduction in life expectancy [1-3]. To generate an experimental model of $\mathrm{CP}$, mice are typically treated with cerulein, a cholecystokinin (CCK) analog. Cerulein-induced CP has been well-characterized and widely used experimental model due to its biochemical, morphological, and pathophysiological similarities to human CP [4-7]. Typical fibrotic proteins that have been observed to express in the pancreas of patients with $\mathrm{CP}$ are $\alpha$-smooth muscle actin ( $\alpha$-SMA) and fibronectin.

$\mathrm{NF}-\mathrm{KB}$ is a transcription factor that is activated during early stages of pancreatitis. It has been reported to regulate genes that influence diverse cellular functions including inflammation and survival. Huang et al. [8] have reported that the extent of NF-KB activation correlates to the severity of acute pancreatitis in mice. Furthermore, they found that prolonged activated state 3 months) leads to $\mathrm{CP}$. Thus, their study suggested that inactivating $\mathrm{NF}-\mathrm{KB}$ might be a promising strategy to treat patients with acute

Received December 8, 2019, Revised December 19, 2019, Accepted December 19, 2019

Correspondence to: Hyeyoung Kim

E-mail: kim626@yonsei.ac.kr, ORCID: Hyeyoung Kim, https://orcid.org/0000-0002-7019-917X

*These authors contributed equally to this work.

**Current affiliation: New Drug Development Center, Daegu-Gyeongbuk Medical Innovation Foundation, Daegu, Korea

Copyright (C) 2019 Korean Society of Cancer Prevention

(c) This is an Open Access article distributed under the terms of the Creative Commons Attribution Non-Commercial License (http://creativecommons.org/licenses/by-nc/4.0) which permits unrestricted non-commercial use, distribution, and reproduction in any medium, provided the original work is properly cited. 
or CP. Previously, Treiber et al. [9] have showed that NF-кB subunit (RelA/p65) is required for fibrosis in a mouse model of $\mathrm{CP}$. Additionally, they observed that myeloid RelA/p65 stimulates pancreatic fibrosis by inducing the expression of collagen and fibronectin in the pancreatic tissues of cerulein-treated mice. Furthermore, inhibition of NF- $\mathrm{KB}$ activation by sulfasalazine has been reported to reduce the expression level of $\alpha$-SMA in pancreatic tissues of diethyldithiocarbamate-treated rats [10].

During pancreatitis, protein kinase Cs (PKCs) are key players that have been reported to contribute in pancreatic damage and inflammation, trypsinogen activation, and basolateral exocytosis [11]. Among PKCs, PKC- $\delta$ has been shown to undergo membrane translocation when stimulated by CCK [12]. Reported PKC- $\delta$-mediated effects of CCK include amylase secretion, trypsinogen activation, and NF- $\kappa \mathrm{B}$ activation in the pancreas $[12,13]$. Thus, PKC- $\delta$ has been proved as an essential protein for mediating NF- $\kappa B$ activation in cerulein- and TNF- $\alpha$-stimulated pancreatic acinar cells [14] and in the pancreatic tissues of mice with acute pancreatitis [15]. Furthermore, Ramnath et al. [15] have suggested that inhibiting $\mathrm{PKC}-\delta$ signifies as a promising prophylactic and/ therapeutic tool for treating acute pancreatitis.

Docosahexaenoic acid (DHA), an omega-3 polyunsaturated fatty acid, is composed of unsaturated fatty acids with 22 carbons and 6 double bonds (C22:6n-3). DHA is naturally found in marine fish oils and nuts [16]. Epidemiological studies have shown a strong correlation between fish consumption and reduction in sudden death from myocardial infarction and cognitive decline $[17,18]$. Studies have shown that DHA exhibits anti-inflammatory and antioxidant activities [19,20]. Moreover, DHA has been reported to have positive effect on diseases such as hypertension, arthritis, atherosclerosis, depression, adult-onset diabetes mellitus, myocardial infarction, hepatic fibrosis, and some types of cancers [17,21-24]. Recently, we reported that DHA supplementation might alleviate acute pancreatitis through its antiinflammatory and antioxidant properties. However, higher doses of DHA were found to have an opposite effect on people with hyperlipidemia [25]. Our previous study showed that pretreatment with DHA (intraperitoneal injection, $13 \mathrm{mg} / \mathrm{kg}$ body weight) suppresses pancreatic edema formation, lipid peroxidation, myeloperoxidase activity, and $\mathrm{NF}-\kappa \mathrm{B}$ activation in pancreatic tissues of cerulein-treated rats. Furthermore, DHA was observed to inhibit PKC- $\delta$ activation and upregulate the expression of antioxidant enzyme, superoxide dismutase 1, in pancreatic tissues of cerulein-treated rats [26].

As expression of fibrotic mediators such as $\alpha$-SMA and fibronectin is mediated by activation of PKC- $\delta$ and NF- $\kappa B$ in the pancreas, we hypothesize that DHA may inhibit the expression of these fibrotic mediators and thereby, prevent $\mathrm{CP}$ pathogenesis.

The purpose of the present study was to investigate whether DHA inhibits pancreatic fibrosis by down-regulating fibrotic mediators ( $\alpha$-SMA and fibronectin) in the pancreas. In addition, we examined whether DHA affects cerulein-induced upregulation of PKC- $\delta$ and NF- $\mathrm{BB}$ in the pancreas of mice with $\mathrm{CP}$.

\section{MATERIALS AND METHODS}

\section{Animals}

Six-week-old C57BL/6 male mice (20-25 g) were obtained from Orient Bio (Orient Bio Inc., Seongnam, Korea). All mice were housed in a climate-controlled room (temperature: $21^{\circ} \mathrm{C} \pm 2.0^{\circ} \mathrm{C}$ and humidity: $50 \% \pm 5 \%$ ) with 12 -hour light-dark cycle and maintained in a pathogen-free facility at Yonsei University. Furthermore, all mice were housed in polypropylene cages with a hardwood chip bedding, and provided food and water ad libitum. They were allowed to acclimatize to laboratory conditions for seven days before commencing the experiment. All experimental procedures were approved by Institutional Animal Care and Use Committee of Yonsei University (IACUC-201607-467-01).

\section{Experimental design}

Mice were randomly divided into three groups $(n=9$ per group): none group (without cerulein treatment), control group (with cerulein treatment alone), and DHA group (with cerulein and DHA co-treatment). DHA ( $10 \mu \mathrm{M}$ dissolved in $0.2 \%$ ethanol) or vehicle control ( $0.2 \%$ ethanol) was added to the drinking water and administered to mice for nine weeks. After three weeks of drinking DHA or vehicle water, one intraperitoneal injection/h for 7 hours was given to mice every week such that each animal received 7 courses of the injury agent, cerulein $(50 \mu \mathrm{g} / 2 \mathrm{~mL} / \mathrm{kg}$ in saline containing $1 \%$ bovine serum albumin (BSA) or vehicle control (saline containing 1\% BSA, $2 \mathrm{~mL} / \mathrm{kg}$ ) every week. Totally, cerulein was given to mice for 6 weeks. All mice were sacrificed 72 hours after the last cerulein injection. Pancreas was collected and examined histologically. Additionally, pancreatic tissue samples were also homogenized in $10 \mathrm{mM}$ Tris buffer $(\mathrm{pH}$ 7.4) for biochemical analyses. Tissue homogenates were assessed for protein expression levels of $\alpha$-SMA and fibronectin by Western blotting. Total RNA was isolated from the pancreas and mRNA expression of $\alpha$-SMA and fibronectin was investigated. The expression levels of PKC- $\delta$ and NF- $\kappa \mathrm{B}$ p 65 in the pancreas were determined using immunohistochemistry. 


\section{Western blot analysis}

Western blotting was performed to evaluate the protein expression levels of $\alpha$-SMA and fibronectin. Pancreatic tissue homogenates (120 $\mu$ g protein/lane) were separated by $8 \%$ to $12 \%$ SDS-PAGE and transferred onto nitrocellulose membranes (Amersham Inc., Arlington Heights, IL, USA) by electroblotting. Membranes were then incubated with antibodies against $\alpha$-SMA (1 : 5,000, sc-53015; Santa Cruz Biotechnology, Dallas, TX, USA), fibronectin (1:100, sc-8422; Santa Cruz Biotechnology), and glyceraldehyde-3-phosphate dehydrogenase (GAPDH) (1:3,000, sc-47724; Santa Cruz Biotechnology) at $4^{\circ} \mathrm{C}$ overnight. Following incubation, membranes were washed with TBS with Tween-20. The primary antibodies were then detected using horseradish peroxidase (HRP)-conjugated secondary antibodies, and visualized using enhanced chemiluminescence detection system (Santa Cruz Biotechnology) according to the manufacturer's instruction. GAPDH was used as loading control. Expression levels were standardized to GAPDH expression level. Further, data were processed and quantified using volume analysis and molecular analysis software, respectively.

\section{Real-time quantitative reverse transcription PCR analysis}

Quantitative reverse transcription PCR was performed to assess mRNA expression of mouse-specific $\alpha$-SMA and fibronectin. Total RNA was isolated from the pancreas, and reverse transcribed into cDNA using random hexamer and reverse transcriptase under following conditions: $23^{\circ} \mathrm{C}$ for 10 minutes, $37^{\circ} \mathrm{C}$ for 60 minutes, and $95^{\circ} \mathrm{C}$ for 5 minutes. Further, CDNA was polymerized using primers specific for $\alpha$-SMA gene, fibronectin gene, and GAPDH. Primer sequences for PCR were as follows: For $\alpha$-SMA gene, forward primer, 5 -GGCTCTGGGCTCTG TAAGG-3' and reverse primer, 5'-CTCTTGCTCTGGGCTTCATC-3', which yielded $149 \mathrm{bp}$ PCR product. For fibronectin gene, the forward primer 5'-CGAGGTGACGAGACCACAA-3' and the reverse primer 5'-CTGGAGTCAAGCCAGACACA-3' were used, which yielded $149 \mathrm{bp}$ PCR product. For GAPDH, the forward primer 5 ACCCAGAAGACTGTGGATGG- $3^{\prime}$ and the reverse primer 5' CACATTGGGGGTAGGAACAC-3' were used, which yielded a 171 bp PCR product. cDNAs were amplified under following conditions: 40 cycles of denaturation at $95^{\circ} \mathrm{C}$ for 15 seconds, annealing at $55^{\circ} \mathrm{C}$ to $65^{\circ} \mathrm{C}$ for 30 seconds, and extension at $72^{\circ} \mathrm{C}$ for 30 seconds. All samples were standardized to GAPDH expression. Results were expressed as fold induction in comparison to the expression level of the none group.

\section{Histological observation}

Remaining portion of the pancreas was fixed overnight at $4^{\circ} \mathrm{C}$ in freshly prepared formaldehyde/PBS (Sigma-Aldrich, St. Louis, MO, USA) ( $\mathrm{pH}$ 7.4). After fixation, tissue was embedded in paraffin, sectioned, and processed for hematoxylin and eosin (Sigma-Aldrich) staining following standard protocol. Multiple microscopic fields were randomly selected from each treatment group and assessed for leukocyte infiltration, acinar cell necrosis, and vacuolization by a pathologist, who was blinded to the treatments.

\section{Immunohistochemistry}

Pancreatic tissue sections ( $4 \mu \mathrm{m}$ thick) were deparaffinized in xylene for 15 minutes, rehydrated using ethanol gradients and antigen retrieved by microwaving at $95^{\circ} \mathrm{C}$ for 5 minutes in $10 \mathrm{mM}$ sodium citrate buffer ( $\mathrm{pH}$ 6.0). Endogenous peroxidase activity was blocked by immersing the slides in peroxidase blocking buffer (3\% hydrogen peroxide) for 10 minutes at room temperature. Further, slides were incubated with blocking buffer ( $5 \% \mathrm{BSA}$ ) for 1 hour at room temperature. Primary antibodies for PKC- $\delta(1: 100$, ab182126; Abcam, Cambridge, UK) and NF-кB p65 (1:100, sc-372; Santa Cruz Biotechnology) were then added and incubated at room temperature for 2 hours. Slides were rinsed in TBS and then, incubated with secondary antibody (k4003, polymer HRP-labelled anti rabbit; DAKO, Glostrup, Denmark) for 20 minutes at room temperature. Slides were again washed in TBS and visualized by incubating with diaminobenzidine substrate for 3 minutes at room temperature. Slides were then washed in distilled water and nuclei was counterstained using Mayer's hematoxylin for 1 minute followed by two rinses in distilled water. Further, slides were dehydrated by serial immersion for 1 minute each in $70 \%$ ethanol and 95\% ethanol followed by 2 minutes each in 100\% ethanol and two changes of xylene. Finally, slides were mounted using Pertex mounting medium and coverslipped.

\section{Statistical analysis}

All values are expressed as means \pm SE for each group $(n=9)$. Statistical significance was assessed using analysis of variance followed by Newman-Keuls post hoc test. $P<0.05$ was considered statistically significant. Statistical analysis was performed using IBM SPSS ver. 24.0 (IBM Corp., Armonk, NY, USA). 


\section{RESULTS}

\section{DHA inhibits cerulein-induced pancreatic damage}

Pancreatic fibrosis is the histological marker for pancreatic damage. In the present study, pancreatic weight/total body weight was used as an index to evaluate pancreatic fibrosis. Weight ratio was found to be decreased following cerulein treatment (Fig. 1A). However, DHA treatment was observed to attenuate the declining ratio of pancreatic weight/total body weight.

\section{DHA inhibits cerulein-induced pancreatic expression of $\alpha$-smooth muscle actin and fibronectin}

To investigate if DHA inhibits cerulein-induced fibrosis in the pancreas, mRNA expression levels of fibrotic mediators, such as $\alpha$-SMA and fibronectin were evaluated using reverse transcription PCR. Cerulein was observed to increase mRNA expression of $\alpha$-SMA and fibronectin in the pancreas (Fig. 1B). Contrary, cerulein-induced mRNA expression was found to be inhibited by DHA. Additionally, we measured protein expression level of $\alpha$-SMA and fibronectin by Western blot analysis. Protein expression levels of $\alpha$-SMA and fibronectin were observed to be increased by cerulein (Fig. 2) while the expression was suppressed on DHA treatment. Our results showed that DHA inhibits $\alpha$-SMA and fibronectin expression in the pancreas of mice treated with cerulein.

\section{DHA inhibits cerulein-induced upregulation of protein kinase $\mathrm{C}-\delta$ and NF- $\mathrm{KB}$ p65 in the pancreas}

As PKC- $\delta$ is upstream of NF- $\mathrm{KB}$ activation, we determined the effect of DHA on cerulein-induced upregulation of PKC- $\delta$ and
A

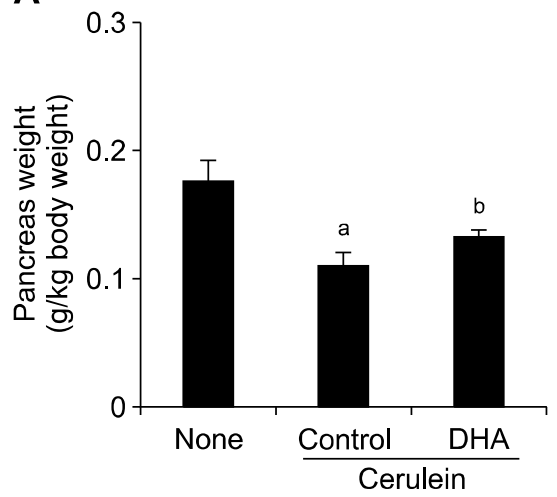

B

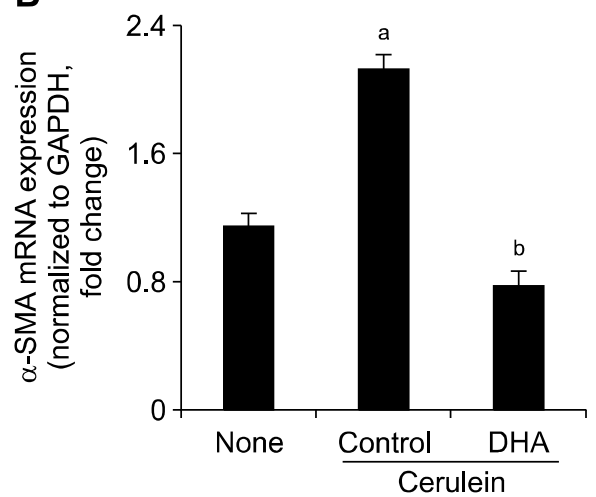

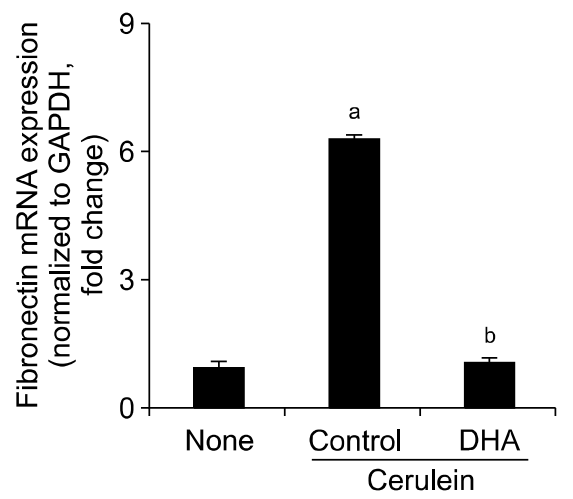

Figure 1. Effect of docosahexaenoic acid (DHA) on pancreatic damage and mRNA levels of $\alpha$-smooth muscle actin ( $\alpha$-SMA) and fibronectin in pancreas. (A) Pancreatic weight and body weight were measured after treatment with cerulein and DHA. (B) mRNA levels of $\alpha$-SMA and fibronectin were determined by reverse transcription-PCR. mRNA expression was normalized to glyceraldehyde-3-phosphate dehydrogenase (GAPDH) expression. None, untreated mice; Control, mice treated with cerulein alone; DHA, mice treated with cerulein and DHA. Values are presented as mean $\pm \mathrm{SE}$. ${ }^{\mathrm{a}} P<0.05$ vs. none group, ${ }^{\mathrm{b}} P<0.05$ vs. control group.
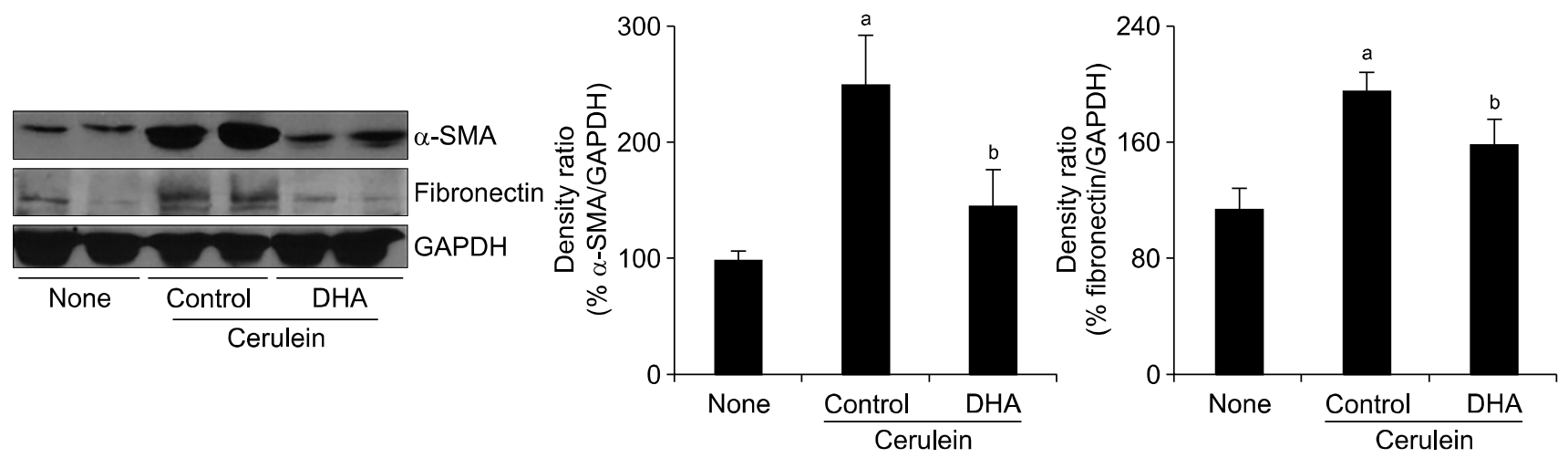

Figure 2. Effect of docosahexaenoic acid (DHA) on protein expression levels of $\alpha$-smooth muscle actin ( $\alpha$-SMA) and fibronectin in pancreas. Protein expression of $\alpha$-SMA, fibronectin, and glyceraldehyde-3-phosphate dehydrogenase (GAPDH) was determined by Western blot analysis. Expression levels of $\alpha$-SMA and fibronectin were compared to that of GAPDH (loading control) and expressed as a percentage ratio of the band density. None, untreated mice; Control, mice treated with cerulein alone; DHA, mice treated with cerulein and DHA. Values are presented as mean \pm SE. ${ }^{\mathrm{a}} P<0.05$ vs. none group, ${ }^{\mathrm{b}} P<0.05$ vs. control group. 


\section{A}
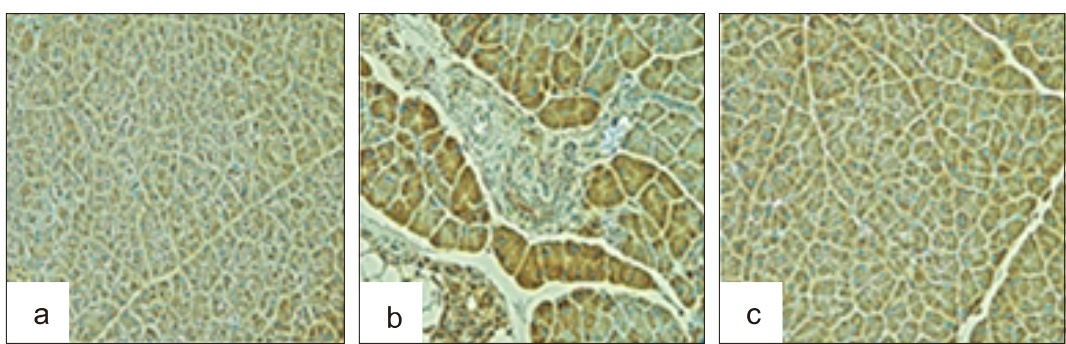

PKC $\delta$
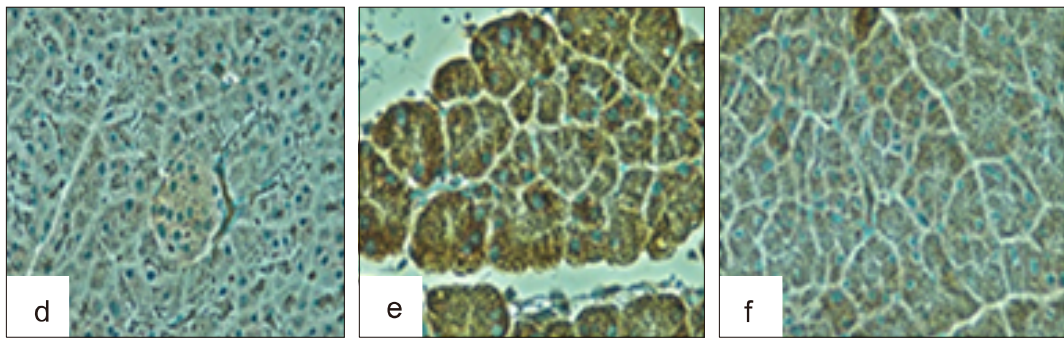

NF-кB

None

Control

DHA

B

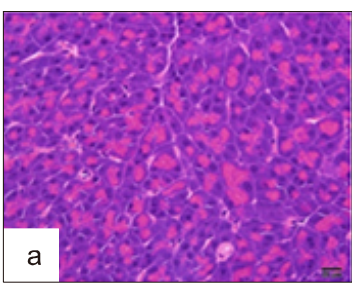

None

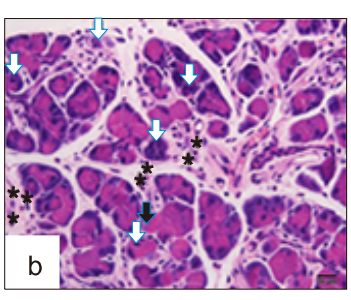

Control

Cerulein

Figure 3. Effect of docosahexaenoic acid (DHA) on the expression levels of protein kinase C delta (PKC- $\delta$ ) and NF-kB, and histological change in pancreas (H\&E, $\times 400$ [scale bar, $20 \mu \mathrm{m}$ ]). (A) Immunohistochemical analysis was performed using anti-PKC- $\delta$ and anti-NF-KB p65 antibodies. (a-c) Representative PKC- $\delta$ expression levels in pancreas. (a) Negligible signals of PKC- $\delta$ expression were detected in none group. (b) Intense signals of PKC- $\delta$ were detected in control group. (c) Few PKC- $\delta$-positive cells were observed in DHA group. (d-f) Representative NF-kB p65

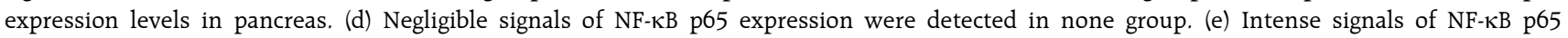
were detected in control group. (f) Few NF- $\mathrm{kB}$ p65-positive cells were observed in DHA group. (B) Histological changes in pancreas. (a) Healthy pancreatic tissue was observed in none group. (b) Abnormal tissue structures including leukocyte infiltration (black small asterisks), necrosis of acinar cells (white bold arrows) and vacuolization (black small arrow) were observed in control group. (c) Reduced acinar cell necrosis, inflammatory cell infiltration, and vacuolization lesions were observed in mice co-treated with cerulein and DHA. None, untreated mice; Control, mice treated with cerulein alone; DHA, mice treated with cerulein and DHA.

NF- $\kappa$ B p65 by immunohistochemistry. Figure 3A illustrates immunohistochemical expression levels of PKC- $\delta$ and NF- $\kappa B$ in the pancreas. We observed faint staining for PKC- $\delta$ and NF- $\kappa B$ in the pancreatic tissues of none group (Fig. 3A-a and 3A-d). Remarkable expression of PKC- $\delta$ and NF- $\kappa \mathrm{B}$ was detected in the pancreas of mice treated with cerulein alone (Fig. 3A-b and 3A-e). However, fewer PKC- $\delta$ - and NF-кB-positive cells were found in the pancreatic tissues of mice treated with cerulein and DHA (Fig. 3A-c and 3A-f) as compared to those in the pancreatic tissues of mice treated with cerulein alone (Fig. 3A-b and 3A-e). Thus, results suggested that DHA suppresses cerulein-induced upregulation of PKC- $\delta$ and NF- $\kappa B$ in the pancreas of mice treated with cerulein.

\section{DHA attenuates cerulein-induced histological chan- ges in the pancreas}

Administering cerulein for six weeks was observed to cause histological changes in the pancreas (Fig. 3B). In the control group (cerulein alone), abnormal tissue structures such as leukocyte infiltration (black small asterisks), necrosis of acinar cells (white bold arrows), and vacuolization (black bold arrow) were evidently observed (Fig. 3B-b), which was reduced on DHA exposure (Fig. 3B-c). Typically, in healthy pancreas, leukocytes are not present. However, leukocyte infiltration has been commonly found in the 
pancreas during CP. In the present study, neutrophils were found in the pancreas of cerulein-treated mice. In CP, pancreatic fibrosis is characterized by reduced number and size of acini and necrotic acini. Figure 3B shows necrotic and damaged acinar cells in cerulein-treated pancreas. Furthermore, vacuolization is an important marker of pancreatic acinar cell damage. In our study, Figure 3B shows vacuoles that were accumulated in the pancreas of cerulein-treated mice. However, these modifications in pancreatic tissues were apparently inhibited by DHA treatment.

\section{DISCUSSION}

In the present study, we found that DHA inhibits ceruleininduced pancreatic damage and expression of fibrotic mediators, such as $\alpha$-SMA and fibronectin in the pancreas. In addition, we observed that cerulein-induced histological changes in the pancreas including inflammatory cell infiltration and acinar cell necrosis were suppressed by DHA. Overall, our results demonstrated the inhibitory effect of DHA on cerulein-induced fibrosis in vivo. Furthermore, cerulein-induced upregulation of PKC- $\delta$ and NF- $\kappa B$ in the pancreas were found to be suppressed by DHA. These results suggested that anti-fibrotic effect of DHA may be mediated with preventing the activation of PKC- $\delta$ and NF- $\kappa B$ in the pancreas.

NF- $\kappa B$ activation during chronic inflammation has been reported to upregulate several inflammatory cytokines and other inflammatory mediators [27-31]. NF- $\kappa \mathrm{B}$ has been shown to mediate high fat diet-related pancreatic fibrosis in rats [32]. Furthermore, inhibition of NF- $\mathrm{KB}$ expression by Eruberin A (2, 3-dehydroflavonoid), a flavanol glycoside isolated from Pronephrium penangianum, has been reported to suppress the expression of fibrotic mediators including $\alpha$-SMA, fibronectin, and type 1-collagen in pancreatic stellate cells [33]. Activation of pancreatic stellate cells is the key commencing step in pancreatic fibrosis, which is a characteristic feature associated with $\mathrm{CP}$. Thus, inhibiting NF- $\kappa \mathrm{B}$ may be therapeutically significant approach. DHA has been shown to inhibit lipopolysaccharide-induced activation of NF- $\kappa B$ in mammary epithelial cells [34], which supports our present findings that DHA reduces NF- $\kappa B$ expression in pancreatic tissues of cerulein-treated mice. It is well known that nuclear translocation of NF- $\mathrm{KB}$ is essential to determine its activation. Therefore, further study needs to be performed to investigate nuclear expression of NF- $\mathrm{KB}$ in pancreatic tissues of cerulein-treated mice with or without DHA using electrophoretic mobility assay or immunohistochemical analysis.

PKC- $\delta$ has been reported as vital for signaling pathway that mediates CCK-induced pancreatitis in pancreatic acinar cells
[13,35]. PKC- $\delta$ has been known to regulate CCK/cerulein-induced $\mathrm{NF}-\kappa \mathrm{B}$ activation in pancreatic acinar cells $[14,15]$. Earlier, we showed that DHA suppresses PKC- $\delta$-mediated activation of NF- $\kappa B$ in pancreatic acinar cells when stimulated with cerulein [26]. These studies demonstrate that $\mathrm{PKC}-\delta$ may regulate the progression of $\mathrm{CP}$ by activating NF- $\mathrm{KB}$ in the pancreas.

Recently, Xue et al. [36] reported that pancreatic fibrosis and pancreatic atrophy are characterized by proliferation of activated pancreatic stellate cells. Choi et al. [37] demonstrated that agents, which downregulate fibrotic mediators including $\alpha$-SMA and fibronectin, also decrease the expression of TGF- $\beta$ in pancreatic tissues and pancreatic stellate cells. Subsequently, such agents can be used for treating CP-related pancreatic fibrosis. Thus, further investigations are required to assess whether DHA can ameliorate the activation of pancreatic stellate cells and TGF- $\beta$ signaling in $\mathrm{CP}$.

In conclusion, DHA suppresses the expression of fibrotic mediators, $\alpha$-SMA and fibronectin in the pancreas of ceruleintreated mice. Furthermore, cerulein-induced upregulation of PKC- $\delta$ and NF- $\kappa B$ in the pancreas can be suppressed by DHA treatment. Overall, our results suggest that consumption of DHA-rich foods may prevent the $\mathrm{CP}$ pathogenesis by suppressing the expression of fibrotic mediators in the pancreas.

\section{ACKNOWLEDGMENTS}

This study was supported by Brain Korea 21 PLUS Project, College of Human Ecology, Yonsei University, Seoul 03722, Republic of Korea.

\section{CONFLICTS OF INTEREST}

No potential conflicts of interest were disclosed.

\section{ORCID}

Sle Lee,

https://orcid.org/0000-0001-8197-1906

Yoo Kyung Jeong,

https://orcid.org/0000-0002-7458-0234

Joo Weon Lim,

https://orcid.org/0000-0001-7483-3820

Hyeyoung Kim,

https://orcid.org/0000-0002-7019-917X 


\section{REFERENCES}

1. Hofbauer B, Saluja AK, Lerch MM, Bhagat L, Bhatia M, Lee HS, et al. Intra-acinar cell activation of trypsinogen during caerulein-induced pancreatitis in rats. Am J Physiol 1998;275:G352-62.

2. Lerch MM, Adler G. Experimental animal models of acute pancreatitis. Int J Pancreatol 1994;15:159-70.

3. Kim H. Cerulein pancreatitis: oxidative stress, inflammation, and apoptosis. Gut Liver 2008;2:74-80.

4. Lerch MM, Gorelick FS. Models of acute and chronic pancreatitis. Gastroenterology 2013;144:1180-93.

5. Ulmasov B, Oshima K, Rodriguez MG, Cox RD, NeuschwanderTetri BA. Differences in the degree of cerulein-induced chronic pancreatitis in C57BL/6 mouse substrains lead to new insights in identification of potential risk factors in the development of chronic pancreatitis. Am J Pathol 2013;183:692-708.

6. Hyun JJ, Lee HS. Experimental models of pancreatitis. Clin Endosc 2014:47:212-6.

7. Willemer S, Elsässer HP, Adler G. Hormone-induced pancreatitis. Eur Surg Res 1992:24 Suppl 1:29-39.

8. Huang H, Liu Y, Daniluk J, Gaiser S, Chu J, Wang H, et al. Activation of nuclear factor- $\mathrm{KB}$ in acinar cells increases the severity of pancreatitis in mice. Gastroenterology 2013;144:202-10.

9. Treiber M, Neuhöfer P, Anetsberger E, Einwächter H, Lesina M, Rickmann M, et al. Myeloid, but not pancreatic, RelA/p65 is required for fibrosis in a mouse model of chronic pancreatitis. Gastroenterology 2011;141:1473-85, 1485.e1-7.

10. Wang YR, Tian FL, Yan MX, Fan JH, Wang LY, Kuang RG, et al. Sulfasalazine inhibits inflammation and fibrogenesis in pancreas via NF- $\kappa$ B signaling pathway in rats with oxidative stress-induced pancreatic injury. Drug Des Devel Ther 2016;10:1743-51.

11. Fleming $A K$, Storz P. Protein kinase $C$ isoforms in the normal pancreas and in pancreatic disease. Cell Signal 2017;40:1-9.

12. Pollo DA, Baldassare JJ, Honda T, Henderson PA, Talkad VD, Gardner JD. Effects of cholecystokinin (CCK) and other secretagogues on isoforms of protein kinase $\mathrm{C}$ (PKC) in pancreatic acini. Biochim Biophys Acta 1994:1224:127-38.

13. Thrower EC, Wang J, Cheriyan S, Lugea A, Kolodecik TR, Yuan J, et al. Protein kinase $\mathrm{C}$ delta-mediated processes in cholecystokinin-8-stimulated pancreatic acini. Pancreas 2009;38:930-5.

14. Satoh A, Gukovskaya AS, Nieto JM, Cheng JH, Gukovsky I, Reeve JR Jr, et al. PKC-delta and -epsilon regulate NF-kappaB activation induced by cholecystokinin and TNF-alpha in pancreatic acinar cells. Am J Physiol Gastrointest Liver Physiol 2004;287:G582-91.

15. Ramnath RD, Sun J, Bhatia M. PKC $\delta$ mediates pro-inflammatory responses in a mouse model of caerulein-induced acute pancreatitis. J Mol Med (Berl) 2010;88:1055-63.

16. Riediger ND, Othman RA, Suh M, Moghadasian MH. A systemic review of the roles of $\mathrm{n}-3$ fatty acids in health and disease. J Am Diet Assoc 2009;109:668-79.

17. Horrocks LA, Yeo YK. Health benefits of docosahexaenoic acid (DHA). Pharmacol Res 1999:40:211-25.

18. Ciappolino V, Mazzocchi A, Botturi A, Turolo S, Delvecchio G, Agostoni $\mathrm{C}$, et al. The role of docosahexaenoic acid (DHA) on cognitive functions in psychiatric disorders. Nutrients 2019;11:E769.

19. Clementi ME, Lazzarino G, Sampaolese B, Brancato A, Tringali G. DHA protects PC12 cells against oxidative stress and apoptotic signals through the activation of the NFE2L2/HO-1 axis. Int J Mol
Med 2019:43:2523-31.

20. Yum HW, Na HK, Surh YJ. Anti-inflammatory effects of docosahexaenoic acid: implications for its cancer chemopreventive potential. Semin Cancer Biol 2016;40-41:141-59.

21. Lytle KA, Depner CM, Wong CP, Jump DB. Docosahexaenoic acid attenuates Western diet-induced hepatic fibrosis in Ldlr-/- mice by targeting the TGF $\beta$-Smad3 pathway. J Lipid Res 2015:56: 1936-46.

22. Holub BJ. Docosahexaenoic acid (DHA) and cardiovascular disease risk factors. Prostaglandins Leukot Essent Fatty Acids 2009;81:199-204.

23. Park M, Kim H. Anti-cancer mechanism of docosahexaenoic acid in pancreatic carcinogenesis: a mini-review. J Cancer Prev 2017:22:1-5.

24. Yun EJ, Song KS, Shin S, Kim S, Heo JY, Kweon GR, et al. Docosahexaenoic acid suppresses breast cancer cell metastasis by targeting matrix-metalloproteinases. Oncotarget 2016;7:49961-71.

25. Jeong YK, Kim H. A mini-review on the effect of docosahexaenoic acid (DHA) on cerulein-induced and hypertriglyceridemic acute pancreatitis. Int J Mol Sci 2017;18:E2239.

26. Jeong YK, Lee S, Lim JW, Kim H. Docosahexaenoic acid inhibits cerulein-induced acute pancreatitis in rats. Nutrients 2017;9: E744.

27. Chen X, Ji B, Han B, Ernst SA, Simeone D, Logsdon CD. NF-kappaB activation in pancreas induces pancreatic and systemic inflammatory response. Gastroenterology 2002;122:448-57.

28. Gukovsky I, Gukovskaya AS, Blinman TA, Zaninovic V, Pandol SJ. Early NF-kappaB activation is associated with hormone-induced pancreatitis. Am J Physiol 1998;275:G1402-14.

29. Han B, Logsdon CD. Cholecystokinin induction of mob-1 chemokine expression in pancreatic acinar cells requires NF-kappaB activation. Am J Physiol 1999;277:C74-82.

30. Hietaranta AJ, Singh VP, Bhagat L, van Acker GJ, Song AM, Mykoniatis A, et al. Water immersion stress prevents caerulein-induced pancreatic acinar cell nf-kappa $b$ activation by attenuating caerulein-induced intracellular $\mathrm{Ca} 2+$ changes. J Biol Chem 2001;276:18742-7.

31. Steinle AU, Weidenbach H, Wagner M, Adler G, Schmid RM. NF-kappaB/Rel activation in cerulein pancreatitis. Gastroenterology 1999;116:420-30.

32. Yan MX, Ren HB, Kou Y, Meng M, Li YQ. Involvement of nuclear factor kappa B in high-fat diet-related pancreatic fibrosis in rats. Gut Liver 2012;6:381-7.

33. Tsang SW, Zhang HJ, Chen YG, Auyeung KK, Bian ZX. Eruberin A, a natural flavanol glycoside, exerts anti-fibrotic action on pancreatic stellate cells. Cell Physiol Biochem 2015:36:2433-46.

34. He X, Liu W, Shi M, Yang Z, Zhang X, Gong P. Docosahexaenoic acid attenuates LPS-stimulated inflammatory response by regulating the PPAR $\gamma / \mathrm{NF}-\mathrm{\kappa B}$ pathways in primary bovine mammary epithelial cells. Res Vet Sci 2017;112:7-12.

35. Gorelick F, Pandol S, Thrower E. Protein kinase $C$ in the pancreatic acinar cell. J Gastroenterol Hepatol 2008;23 Suppl 1:S37-41.

36. Xue R, Jia K, Wang J, Yang L, Wang Y, Gao L, et al. A rising star in pancreatic diseases: pancreatic stellate cells. Front Physiol 2018; 9:754.

37. Choi JW, Lee SK, Kim MJ, Kim DG, Shin JY, Zhou Z, et al. Piperine ameliorates the severity of fibrosis via inhibition of TGF- $\beta / \mathrm{SMAD}$ signaling in a mouse model of chronic pancreatitis. Mol Med Rep 2019;20:3709-18. 